Revista de Estudios Histórico-Jurídicos

[Sección historia de las instituciones]

XLII (Valparaíso, Chile, 2020)

[pp. 811-832]

\title{
LA MORTALIDAD INFANTIL A TRAVÉS DEL DELITO DE INFANTICIDIO Y EL ABANDONO DE MENORES, SANTIAGO $1873-1920$
}

[Infant mortality through the crime of infanticide and the abandonment of minors, Santiago 1873-1920]

\author{
Pablo CHÁvez ZúNigA* \\ Universidad de Chile \\ Víctor BRANGIER PeÑAILILlo** \\ Universidad de Chile
}

\section{RESUMEN}

Este artículo establece vínculos entre los delitos relacionados con la infancia y la mortalidad infantil, como marco cultural que da cuenta del perfil social de los involucrados en los delitos y los métodos que aplicó la justicia para investigar en estos sumarios. A través de un cuerpo documental de 126 expedientes judiciales caratulados como muertes de párvulos, infanticidio y abandono, se analizarán los modos de crianza y la falta de cuidados en la infancia como factores de las muertes. Tanto los testimonios como los juicios legales conforman una narrativa que permite indagar acerca de la ocurrencia de actos violentos y ayuda a comprender, también los procesos de construcción de los significados de la niñez, desde un acercamiento marcado por las orientaciones de la justicia y la ciencia médica legal.

\section{Abstract}

This article establishes links between crimes related to childhood and infant mortality, as a cultural framework that accounts for the social profile of those involved in the crimes and the methods that justice applied to investigate in these summaries. Through a documentary body of 126 judicial files categorized as kindergarten deaths, infanticide and abandonment, ways of raising children and lack of care in childhood will be analyzed ad factors in deaths. Both the testimonies and legal judgments make up a narrative that allows us to investigate the occurrence of violent acts and helps to understand, also the processes of construction of the meanings of childhood, from an approach marked by the orientations of justice and science legal medical.

* Doctor en Historia, Universidad de Chile. Agradezco el financiamiento otorgado por la Comisión Nacional de Investigación Científica y Tecnología (CONICYT), a través de su programa formación de capital humano avanzado: Beca de Doctorado Nacional (2015-2019). Correo electrónico: pablo.chavez.zuniga@gmail.com

** Doctor en Historia, Universidad de Chile. Académico Universidad Bernardo O'Higgins. Centro de Estudios Históricos, Avenida Fábrica 1990, Santiago, Chile. Correo electrónico: vmbrangi@gmail.com 
También se precisan las estrategias de los actores durante los sumarios judiciales y las razones a las que respondían por sus actos. Las conclusiones destacan la riqueza documental de las investigaciones judiciales para relevar una de las aristas más violentas dirigidas hacia la infancia.

Palabras clave

Mortalidad Infantil, Infanticidio, Santiago.
It also requires the strategies of the actors during the judicial proceedings and the reasons to which they responded for their actions. The conclusions highlight the documentary wealth of judicial investigations to reveal one of the most violent edges directed towards childhood.

\section{KeY Words}

Child Mortality, Infanticide, Santiago.

RECIBIDO el 19 de marzo de 2019 y ACEPTADO el 12 de marzo de 2020

\section{INTRODUCCIÓN}

En este artículo se analizan los relatos de diversos actores que responden a los interrogatorios relativos a la ausencia de cuidados en los párvulos por parte de sus familiares; se examinan, además, las circunstancias de los fallecimientos de niños y la mirada jurídico médica de la mortalidad infantil, trabajo basado en la revisión de expedientes judiciales criminales caratulados de infanticidio y los sumarios por muertes de menores, además el estudio de los libros médico legales y notas de prensa. A continuación, se examinan los métodos empleados por la medicina y la justicia para resolver estas investigaciones criminales. Desde una perspectiva jurídica, en el desarrollo de este trabajo se intenta comprender los significados de la infancia a partir de las huellas generadas en estos hechos violentos.

El estudio de los delitos relacionados con la infancia es relevante por varias razones; permite ingresar a las manifestaciones cotidianas de los vínculos madrehijo, también da cuenta de una época caracterizada por el desapego, la falta de cuidados y el abandono. Estos elementos representan una de las principales expresiones culturales sobre la niñez durante la segunda mitad del siglo XIX, lo que conforma una estructura social donde la medicina, las leyes y las autoridades recién comienzan a ocuparse de legislar ante este grave problema. En el ámbito de la justicia, estaban definidas y delimitadas las categorías de agresiones violentas hacia los párvulos, con sus respectivos castigos. Sin embargo, en la praxis tuvieron escasas repercusiones y el maltrato de las madres o los responsables de los niños originó conflictos, que se analizan en este artículo y que permiten acceder a la trayectoria de los descuidos hacia la infancia, desde la mirada de la justicia.

Los registros documentales para conformar el material de estudio de esta investigación están constituidos por los expedientes judiciales conservados en distintos Fondos del Archivo Nacional Histórico de Chile, específicamente, el juzgado del crimen y el juzgado de letras de Santiago para los años entre 1873 y 1920 . Estos registros son relevantes dado que en ellos se encuentran argumentaciones sobre las causas, las explicaciones acerca de las muertes de los niños y las narrativas de los funcionarios médicos y judiciales. Entre los testigos, jueces y litigantes se produjo un intercambio de posiciones a lo largo de los juicios, estableciéndose una relación 
entre estos actores a través del lente de la justicia ${ }^{1}$. Sus legajos contienen informes provenientes de los hospitales de la zona, en los cuales quedaron explicitados los tratamientos médicos aplicados a los enfermos y los testimonios en caso que provocaran un deceso. Esta fuente permite acceder a varios ámbitos relativos a las formas de mortalidad que eran consideradas de carácter violento, tales como infanticidios, abandonos con resultado de muerte y accidentes.

Entendiendo esta óptica desde los trabajos elaborados por el derecho, "nuestro país ostenta la triste vanagloria de ocupar uno de los primeros lugares del mundo respecto del porcentaje de la mortalidad infantil [...] no hay duda que en la primera infancia la carencia de cuidados prolijos, son los factores que influyen más de cerca para dar a nuestra patria tan enorme número; pero es preciso advertir, también, que ello en parte de debe a la comisión frecuente, y explicable por las dificultades para llevar a cabo su pesquisa, de aquellos delitos que atentan contra la vida de los párvulos, especialmente del infanticidio y del aborto" ${ }^{2}$. Rastrear las colisiones entre el planteamiento de las leyes y el comportamiento de las personas en el caso de los delitos señalados, es una entrada para reflexionar acerca de las transformaciones culturales que constituyeron las prácticas de asistencia en los infantes y, con ello, la disminución de la mortalidad infantil.

Según el Código Penal, artículo 394: "cometen infanticidio el padre, la madre o los demás ascendientes legitimos o ilegitimos que dentro de las 48 horas después del parto matan al hijo o descendiente, y serán penados con presidio mayor en sus grados mínimo a medio". Así, el infanticidio es cuando se da muerte a un menor de hasta dos días de nacido por sus ascendientes directos. Así, el infanticidio es cuando se da muerte a un menor de hasta dos días de nacido por sus ascendientes directos. En este caso, la ejecución del crimen presentaba como atenuante, el estado de "excitación del cuerpo y del espíritu en que se encuentra la mujer durante el

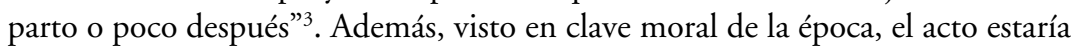
justificado por el deseo de ocultar la deshonra de un parto ilegítimo, por eso la ley consideraba cuarenta y ocho horas siguientes al parto, el crimen cometido después de ese límite sería tipificado como homicidio ${ }^{4}$.

${ }^{1}$ Para Carlo Ginzburg existe una distinción cultural entre el juez interrogador y el sujeto interrogado, aunque ambos plasman sus narrativas sin un filtro en sus diálogos. Así, la fuente judicial registraría dos voces de manera genuina sin la presencia de una mediación u otro actor que interprete sus palabras. Ginzburg, Carlo, Tentativas (Rosario, Prohistoria Ediciones, 2004), p. 224.

${ }^{2}$ Domínguez Larraín, Manuel, El infanticidio desde el punto de vista penal y médico legal (Santiago, Memoria de prueba para optar al grado de licenciado en la Facultad de Leyes y Ciencias Políticas, Universidad de Chile, Sociedad Imprenta y Litografía Universo, 1922), p. 8.

${ }^{3}$ Puga Borne, Federico, Compendio de medicina legal adaptado a la lejislación chilena (Santiago, Imprenta Cervantes, 1896), pp. 143-144.

${ }^{4}$ Para una discusión, desde la medicina, véase GAJARDO, Samuel, Medicina legaly psiquiatría forense, IV: Del infanticidio (Santiago, Editorial Nacimento, 1931), pp. 142-234. También, GaJARDO, Samuel, Definiciones y sintesis de medicina legal (Santiago, Editorial Universo, 1946), pp. 106-112; Avilés MejÍAs, Víctor, Obstetricia forense (Santiago, Ediciones de Derecho Moderno, 1968), pp. 69-99; Didier, Alejandra, DreCKMANn, Alejandra y García, Jackeline, No olvidar el montón de pequeños cuerpos enterrados sin nombre: muerte de niños a través de protocolos de 
Desde esta perspectiva, la lectura de Milanich otorga sustrato a las declaraciones, los testigos y los perfiles de los involucrados. Es, en consecuencia, un enfoque cultural que articula las explicaciones del hecho en la comunidad y sus relaciones con lo jurídico. Además, se complejizan las características técnicas de las investigaciones científico criminales, entre los actos denunciados y los hipotéticamente periciados 5 . Este contraste, en ocasiones se ha obstaculizado la apreciación de los motivos de un infanticidio o un aborto y la posibilidad de obtener evidencias que permitieran llegar a los culpables, ya que los conocimientos de medicina legal no eran suficientes para desentrañar las actuaciones delictuales.

En Santiago, la violencia hacia la niñez, el infanticidio y el abandono eran percibidos como hechos comunes y bastante recurrentes. Nara Milanich destaca la penalización de este delito, definido como parricidio hasta la promulgación del Código Penal en 1874 y, desde ahí la autora profundiza acerca del uso del término infanticidio, ya que los jueces, abogados y testigos emplearon estas definiciones para aludir al delito de abandono o aborto ${ }^{6}$. Otro de los planteamientos consiste en que el Estado liberal, a pesar de propugnar como principio la igualdad de los individuos, dejó en el aspecto legal la distinción entre los nacidos dentro o fuera de un matrimonio, manteniendo las categorías de exclusión en que se encontraban las personas desde el nacimiento ${ }^{7}$.

A nivel teórico, el infanticidio no era visto como cualquier otro modo de asesinato, y no solo desde el punto de vista penal; sino que la participación de la madre como sujeto activo del crimen provocaba confusión a nivel comunal ${ }^{8}$. En los códigos del siglo XIX, este crimen hacía recaer en las mujeres la culpabilidad moral y la responsabilidad económica de la maternidad, situación influenciada por las definiciones de honor, ilegitimidad ${ }^{9}$ y la denominada voz pública que otorgó

autopsia de la Morgue de Santiago (1910-1912), en Investigación forense (Servicio Médico Legal), 2 (2011), pp. 43-60.

${ }^{5}$ Milanich, Nara, Entrañas mil veces despreciables e indignas. El infanticidio en el Chile tradicional, en Dimensión histórica de Chile, 13-14 (Santiago, 1997-1998), pp. 63-82.

${ }^{6}$ Ibíd.

${ }^{7}$ Milanich, Nara, Children of fate. Childhood, class, and the State in Chile, 1850-1930 (Durham, Duke University Press, 2009); también véase la reseña de Whipple, Pablo, De hijos del azar a hijos de la patria. Filiación y desigualdades de clase en Chile, en $A$ Contracorriente. Una revista de historia social y literatura de América Latina, 3 (2010), pp. 382-388.

${ }^{8}$ Di Blasio, María Pina, L'infanticidio nella legislazione penale: uno sguardo al passato per capire il presente, en Giurisprudenza Penale (2016). En línea: http://www.giurisprudenzapenale. $\mathrm{com} / 2016 / 03 / 23 /$ linfanticidio-nella-legislazione-penale-uno-sguardo-al-passato-capirepresente/ [revisado el 23 de junio de 2018]; OLIVIERI, Ilaria, L'infanticidio tra percezione popolare e trattamento giuridico: Prignano 1889, en Storicamente, 6 (2010). En línea: http:// dx.doi.org/10.1473/stor71 [revisado el 12 de junio de 2017]; Casarini, María Pía, Maternità e infanticidio a Bologna: fonti e linee di ricerca, en Quaderni Storici, 49 (1982), pp. 275-284; HUNECKE, Volker, Intensità e fluttuazioni degli l'abbandoni dal XV al XIX secolo. Enfance abandonée et société en Europe (Rome, École Française en Rome, 1991).

${ }^{9}$ Vargas Guerra, Eduardo, La ilejitimidad en Chile i sus consecuencias (Santiago, Memoria de prueba para optar al grado de licenciado en la Facultad de Leyes i Ciencias Políticas de la Universidad de Chile, Imprenta Camilo Henríquez, 1917), p. 16; IpINZA BESOAín, Arnaldo, De la natalidad ilegitima. Sus causas y modo de remediarlas (Santiago, Memoria de prueba para optar al grado de licenciado en la Facultad de Leyes y Ciencias Políticas de la Universidad de Chile, 
mayor repercusión a estos quiebres ${ }^{10}$. A su vez, René Salinas y Manuel Delgado ${ }^{11}$ establecen la hipótesis del cambio de actitud de las madres hacia los hijos expresado en mayores sentimientos de aprecio, lo que descartaría las alternativas del infanticidio y aborto para deshacerse de los niños. Así se optó por abandonar al infante, no arruinando la posibilidad de desarrollo en una institución de protección.

Para calcular la tasa de mortalidad infantil se consideraron las anotaciones de la Iglesia (1873-1884), la que estimó los fallecimientos de menores de siete años y los datos del Registro Civil (1885-1920) cuyo criterio de clasificación tuvo en cuenta las defunciones entre el nacimiento y el año de vida. Entre los años que cubre el estudio, la tasa marcó índices sobre los 300 por cada 1.000 niños que fallecieron antes de superar la etapa consignada como infancia. Así, los primeros meses de vida era la etapa con mayores peligros y más crítica de la sobrevivencia. Justamente, tanto abogados como médicos -entre las variables principales de estas elevadas cifras destacaban que los vínculos madre-hijo se caracterizaban por el desapego-, la falta de cuidados, el abandono y los maltratos.

Tabla 1. Cálculo tasa de mortalidad infantil, provincia de Santiago 1873-1920

\begin{tabular}{|c|c|c|c|c|c|c|c|}
\hline Años & $\begin{array}{c}\text { Nacimien- } \\
\text { tos }\end{array}$ & $\begin{array}{c}\text { Falleci- } \\
\text { mientos } \\
\text { menores 7 } \\
\text { años }\end{array}$ & $\begin{array}{c}\text { Mortalidad } \\
\text { Infantil }\end{array}$ & Años & Nacimientos & $\begin{array}{c}\text { Falleci- } \\
\text { mientos } \\
\text { menores 1 } \\
\text { año }\end{array}$ & $\begin{array}{c}\text { Mor- } \\
\text { talidad } \\
\text { Infantil }\end{array}$ \\
\hline $\mathbf{1 8 7 3}$ & 17.626 & 7.643 & 433.6 & $\mathbf{1 8 8 5}$ & 5.390 & 2.488 & 461.6 \\
\hline $\mathbf{1 8 7 4}$ & 16.748 & 7.368 & 439.9 & $\mathbf{1 8 8 7}$ & 4.744 & 1.544 & 325.5 \\
\hline $\mathbf{1 8 7 6}$ & 16.665 & 9.476 & 568.6 & $\mathbf{1 8 8 8}$ & 7.526 & 2.868 & 381.1 \\
\hline $\mathbf{1 8 7 7}$ & 16.109 & 7.744 & 480.7 & $\mathbf{1 8 8 9}$ & 14.912 & 5.181 & 347.4 \\
\hline $\mathbf{1 8 7 8}$ & 15.414 & 8.289 & 537.8 & $\mathbf{1 8 9 6}$ & 8.523 & 4.093 & 480.2 \\
\hline $\mathbf{1 8 7 9}$ & 17.340 & 8.487 & 489.4 & $\mathbf{1 9 0 9}$ & 18.602 & 8.316 & 447.0 \\
\hline $\mathbf{1 8 8 0}$ & 17.557 & 10.170 & 579.3 & $\mathbf{1 9 1 2}$ & 21.209 & 8.339 & 393.2 \\
\hline $\mathbf{1 8 8 1}$ & 18.432 & 7.924 & 430.0 & $\mathbf{1 9 1 5}$ & 21.803 & 7.193 & 330.0 \\
\hline $\mathbf{1 8 8 2}$ & 18.256 & 8.207 & 449.6 & $\mathbf{1 9 1 7}$ & 25.278 & 7.863 & 311.1 \\
\hline $\mathbf{1 8 8 3}$ & 18.014 & 7.313 & 406.0 & $\mathbf{1 9 1 9}$ & 24.081 & 8.990 & 373.3 \\
\hline $\mathbf{1 8 8 4}$ & 14.235 & 4.308 & 302.6 & $\mathbf{1 9 2 0}$ & 24.628 & 7.542 & 306.2 \\
\hline
\end{tabular}

Fuente: Elaboración propia a partir del Anuario Estadistico de la República de Chile, 1873-1920.

Imprenta San José, 1920); Higginbotham, Ann, Sin of the age: infanticide and illegitimacy in Victorian London, en Victorian Studies, 3 (1989), pp. 319-337; ReVUELTA, Bárbara, Abandoned and illegitimate, a double mortality penalty? Mortality of illegitimate infants in the foundling hospital of Madrid, La Inclusa (1890-1935), en Journal The History of the Family, 18 (2013), pp. 44-67.

${ }^{10} \mathrm{~A}$ partir de las relaciones sociales de las mujeres, fundadas por el orden cristiano, las mujeres fueron posicionadas según el vínculo que mantuvieron con un hombre, ya sea el padre o el esposo. Esta categoría María Eugenia Albornoz la sustenta a partir de los conflictos judiciales generados por las acusaciones de injurias, donde las palabras adquirían gran importancia como pruebas de estas transgresiones judiciales. Albornoz, María Eugenia, Experiencias de conflicto: subjetividades, cuerpos y sentimientos en Chile, siglos XVIII y XIX (Santiago, Acto Editores, 2015).

${ }^{11}$ Salinas, René y Delgado, Manuel, Los hijos del vicio y del pecado: la mortalidad de los niños abandonados (1750-1930), en Proposiciones, 19 (1990), pp. 44-54. 


\section{LAS CARACTERÍSTICAS DE LOS REGISTROS JUDICIALES Y EL PERFIL SOCIAL DE LOS INVOLUCRADOS}

Los delitos que afectaron a los infantes no presentaban certezas científicas en la producción de las pruebas ni en las capacidades jurídicas de establecer penalmente los maltratos. Las indagaciones solo se limitaban a la aplicación de la autopsia médico legal y a la declaración de testigos; con estas diligencias y la baja calidad de las evidencias resultaba complejo llegar a la construcción de los hechos y, más aún, individualizar a una persona determinada como responsable de los actos. A pesar de esta situación, los sumarios judiciales son enriquecedores para iluminar los testimonios acerca de los tratos dedicados a los párvulos.

Tabla 2. Características de los expedientes judiciales por delitos contra la infancia, juzgado del crimen de Santiago, 1873-1920

\begin{tabular}{|l|c|c|c|c|c|c|c|c|c|c|c|c|}
\hline $\begin{array}{l}\text { Definición } \\
\text { Delito }\end{array}$ & $\begin{array}{c}\text { Nú- } \\
\text { mero } \\
\text { casos }\end{array}$ & $\begin{array}{c}\text { Extensión } \\
\text { de } 16 \\
\text { y más } \\
\text { fojas }\end{array}$ & $\begin{array}{c}\text { Extensión } \\
\text { de } 16 \\
\text { y más } \\
\text { fojas }\end{array}$ & $\begin{array}{c}\text { Duración } \\
\text { proceso } \\
\text { de a } 30 \\
\text { días }\end{array}$ & $\begin{array}{c}\text { Dura- } \\
\text { ción } \\
\text { Proceso } \\
\text { de } 1 \text { a } 6 \\
\text { meses }\end{array}$ & $\begin{array}{c}\text { Dura- } \\
\text { cón } \\
\text { más de } \\
6 \text { meses }\end{array}$ & $\begin{array}{c}\text { Apli- } \\
\text { cación } \\
\text { autop- } \\
\text { sia }\end{array}$ & $\begin{array}{c}\text { No } \\
\text { aparece } \\
\text { autop- } \\
\text { sia }\end{array}$ & $\begin{array}{c}\text { Sentencia, } \\
\text { sobresédo } \\
\text { definitiva- } \\
\text { mente }\end{array}$ & $\begin{array}{c}\text { Sentencia, } \\
\text { sobreseído } \\
\text { temporal- } \\
\text { mente } \\
\text { oarchivado }\end{array}$ & $\begin{array}{c}\text { Senten- } \\
\text { cia, } \\
\text { Conde- } \\
\text { nado }\end{array}$ & $\begin{array}{c}\text { Senten- } \\
\text { cia, } \\
\text { no } \\
\text { aparece } \\
\text { precisado }\end{array}$ \\
\hline $\begin{array}{l}\text { Sumario } \\
\text { sobre muerte } \\
\text { párvulo }\end{array}$ & 90 & 88 & 2 & 41 & 45 & 4 & 87 & 3 & 20 & 61 & & 9 \\
\hline Infanticidio & 17 & 9 & 8 & 4 & 7 & 6 & 17 & & 1 & 5 & 11 & \\
\hline Homicidio & 5 & 3 & 2 & 1 & 2 & 2 & 5 & & & 1 & 4 & \\
\hline $\begin{array}{l}\text { Hallazgo de } \\
\text { un feto }\end{array}$ & 5 & 5 & & 2 & 2 & 1 & 5 & & & 5 & & \\
\hline Parricidio & 2 & 2 & & & 1 & 1 & 2 & & & 1 & 1 & \\
\hline Otros ${ }^{12}$ & 7 & 5 & 2 & 2 & 5 & & 4 & 3 & 3 & 3 & & 1 \\
\hline Total & 126 & 112 & 14 & 50 & 62 & 14 & 120 & 6 & 24 & 76 & 16 & 10 \\
\hline
\end{tabular}

Fuente: Elaboración propia, a partir de los expedientes criminales por delitos contra la infancia llevadas a cabo por el juzgado del crimen de Santiago entre 1873 y 1920.

Un indicador necesario para caracterizar el corpus documental se conforma a partir de la cuantificación y las definiciones de los delitos investigados por la justicia. El total de expedientes de la muestra es de 126 procesos, tramitados en ambos juzgados. Las cifras consideradas en la tabla $n^{\circ} 2$, para abarcar un grupo representativo de los delitos relacionados con la infancia corresponden, principalmente, a los caratulados como sumarios sobre la muerte de un párvulo, cuyo propósito era esclarecer las circunstancias o hallar los responsables de las muertes. Debido a lo anterior, no había necesidad de abrir estas causales con alguna individualización, más bien, comenzaban con la búsqueda enfocada en dar con

${ }^{12}$ La categoría “otros” está compuesta por los siguientes delitos: abandono de menor, lesiones, reclamo del oficial del Registro Civil, inhumación indebida, tormentos de tres niños, aborto, envenenamiento y ejercicio ilegal de la medicina. 
el autor del delito. A su vez, los litigios judiciales clasificados como homicidio y parricidio reflejan figuras penales de transición durante la implementación del Código Penal. Tras su aplicación, ambos delitos quedaron comprendidos bajo el nombre de infanticidio. El conjunto de los designados como "otros", fueron los definidos como abandono, lesiones, tormentos, aborto o inscripción de la defunción después del tiempo fijado por ley. Sin embargo, la designación del sumario no tenía mayores diferencias con las diligencias llevadas a cabo en otros delitos, por ejemplo, los sumarios sobre muertes de párvulos abarcaron situaciones de abandono, lesiones, abortos y malos tratos.

La tercera y cuarta columna de la tabla no 2 entrega información acerca del número de fojas contenidas por cada expediente; se observa que la tramitación fue breve. Entre las diligencias recurrentes se encuentra la presentación del delito por algún guardia de policía, que incluía la apertura del proceso, la ejecución de la autopsia y las resoluciones adoptadas por la autoridad judicial. Ante la ausencia de una persona contra quien formular cargos, generalmente, era llamado a la presencia judicial solo el funcionario policial, para confirmar los hechos relatados en el parte. Así, de los 126 procesos que representan la muestra documental, 112 sumarios tuvieron una extensión que va entre una y quince fojas. A continuación, van otros 14 contienen más de quince fojas. De ese modo, el 88,8\% de los litigios incluye entre una y quince fojas. En éstos casos, el desarrollo del juicio convocaba una serie de actores que participaron como testigos, peritos o procuradores, apelando a las rebajas de las condenas. Además, el tránsito de la causa por diversas instancias, como el juzgado del crimen y la Corte de Apelaciones contribuyó a la amplitud de los expedientes.

A continuación, entre la columna quinta y séptima aparece información acerca de la duración de las investigaciones, considerando el plazo entre la descripción inicial del delito, generalmente por la policía que servía al juez como auto cabeza de sumario, hasta que se dictaba la sentencia. De las 126 causas que conforman la muestra, 50 finalizaron en plazos inferiores a un mes. Además, 62 litigios concluyeron antes de los seis meses, lo que equivale al 49,2\%. En cuanto a los delitos que involucraron a la infancia, la producción judicial se limitó a consignar las declaraciones de testigos, agregando la autopsia como prueba para acreditar las denuncias.

La práctica de las autopsias fue el centro en las investigaciones de los expedientes judiciales. En las columnas ocho y nueve de la tabla aparece la ejecución de esta operación en 120 ocasiones, de los 126 totales, lo que representa el 95,2\%. Esta mayoría abrumadora permite afirmar que las necropsias tenían por objeto respaldar las decisiones de los jueces y otorgar un valor científico al momento de generar las sentencias. Esta tramitación resume los vínculos entre la justicia y una incipiente medicina legal. Prueba de ello es que los médicos que llevaron a cabo estas operaciones no contaban con una especialidad científica y sus informes eran bastante sucintos, solo en algunas oportunidades agregaron análisis pulmonares para confirmar la existencia de respiración. Como se profundiza más adelante, las autopsias, en esos años, se efectuaban con tecnologías precarias, sin protocolos definidos y, frecuentemente, sin informes detallados.

Entre las columnas diez y trece de la tabla figuran las sentencias sobre los 
delitos relacionados con la infancia, la mayoría de ellos concluyeron con el sobreseimiento temporal o definitivo. Fueron el corolario de los métodos aplicados y las herramientas técnicas empleadas en las investigaciones. A partir del estudio de los expedientes judiciales es posible comprobar que los responsables no fueron condenados y en reiteradas ocasiones ni siquiera fueron encontrados, confirmando la crítica de los periódicos de la época y, en reiteradas oportunidades, ni siquiera fueron encontrados. La aplicación de penas concentró una parte mínima de los fallos, solo 16 casos que equivalen al 12,7\% de la muestra, cuyas duraciones variables estuvieron entre los 61 días y los 8 años de internación en la casa correccional. Solo un litigio terminó con el traslado de una mujer a la casa de orates. Ante estos hechos la justicia argumentaba que no llegaban a constituir las pruebas para conseguir la condena de un culpable. A pesar de la gravedad de los delitos, éstos finalizaban en la impunidad; tampoco se cumplía la función social y pedagógica de la justicia letrada, es decir, mediante una pena ejemplar impedir la repetición del crimen.

Tabla 3. Características de los imputados que aparecen expedientes judiciales por delitos contra la infancia, juzgado del crimen de Santiago, 1873-1920

\begin{tabular}{|l|c|c|c|c|c|c|c|c|c|c|c|}
\hline $\begin{array}{l}\text { Edad } \\
\text { (años) }\end{array}$ & $\begin{array}{c}\text { Imputa- } \\
\text { do iden- } \\
\text { tificado }\end{array}$ & Mujer & $\begin{array}{c}\text { Hom- } \\
\text { bre }\end{array}$ & Soltera & Casada & Viuda & $\begin{array}{c}\text { Sabe leer } \\
\text { y escribir }\end{array}$ & $\begin{array}{c}\text { Solo } \\
\text { firma } \\
\text { o lee }\end{array}$ & $\begin{array}{c}\text { No sabe } \\
\text { leer ni } \\
\text { escribir }\end{array}$ \\
$\begin{array}{c}\text { Pri- } \\
\text { mera } \\
\text { vez } \\
\text { preso }\end{array}$ & $\begin{array}{c}\text { Más de } \\
\text { una vez } \\
\text { preso }\end{array}$ \\
\hline $15-20$ & 9 & 8 & 1 & 9 & & & 3 & 2 & 4 & 9 & \\
\hline $21-25$ & 13 & 12 & 1 & 12 & & 1 & 2 & 2 & 9 & 13 & \\
\hline $26-30$ & 3 & 3 & & 2 & & 1 & 1 & 1 & 1 & 3 & \\
\hline $30-35$ & 2 & 2 & 1 & & 1 & 1 & & 1 & 2 & \\
\hline $36-40$ & 3 & 2 & 1 & 1 & 1 & 1 & & & 3 & 2 & 1 \\
\hline $41-50$ & 1 & & 1 & 1 & & & & & 1 & & 1 \\
\hline Total & 31 & 25 & 6 & 26 & 1 & 4 & 7 & 5 & 19 & 29 & 2 \\
\hline
\end{tabular}

Fuente: Elaboración propia, a partir de los expedientes criminales por delitos contra la infancia llevadas a cabo por el juzgado del crimen de Santiago entre 1873 y 1920.

La tabla no 3 da cuenta de la identificación de los responsables; en esta época la justicia solo pudo perseguir estos delitos cuando existía flagrancia o confesión de los reos. De acuerdo con el total de expedientes judiciales, solo en 31 sumarios fue identificado un responsable, lo que equivale a que tres cuartos $(75,4 \%)$ de los sumarios concluyó sin hallar un culpable o contra quien formular cargos. Esta información permite detallar las dificultades de la justicia para aprehender a las personas y generar pruebas contra los involucrados. Carencias solo fomentaron la impunidad de las faltas. Las críticas de la prensa hacia los funcionarios judiciales a la forma con que se llevaron a cabo las investigaciones, durante el período, cons- 
tatan que las policías y los jueces solo podrían establecer condenas en la medida que fueran mejoradas las herramientas para desempeñar su labor.

En la tabla no 3, se advierte que, la mayoría de los responsables pertenecía al sexo femenino, sea por la confesión de un embarazo y posterior abandono o por haber efectuado una agresión al párvulo. En los hombres, las imputaciones correspondían a actos violentos como golpes o atropellos con algún medio de transporte. A simple vista, las individualizaciones fueron minoría en relación al total de sumarios, este factor incidió en las sentencias pues no existía un responsable para llevar a juicio. Entre las causas tramitadas que identificaron a una persona, siguiendo lo expresado en las columnas tres y cuatro, el 80,6\% correspondía a mujeres y $19,4 \%$ a hombres. La tabla demuestra que la población femenina era un segmento significativo en la participación de estos procesos; se establece una relación de género, donde legalmente se atribuye a ellas el cuidado y, en este caso, el peso de las acusaciones de maltratos hacia los niños.

En cuanto a la edad, la mayoría de los sospechosos ante la justicia se encontraba en los primeros tramos del rango etario. Según la primera columna de la tabla, de los 31 casos en que fue declarada la edad de los investigados, en 22 de ellos tenían entre 15 y 25 años, lo que equivale al 70,9\% de los procesos. En esa línea, las cifras confirman la participación de jóvenes como imputados en los delitos, justamente, corresponde a la etapa reproductiva en ambos sexos. A nivel judicial, los investigados podían señalar una edad que no correspondía con la real, factor que permitiría una variación de la responsabilidad penal en una época donde resultaba complejo llevar a cabo peritajes seguros acerca de la edad exacta.

Las columnas quinta a la séptima de la tabla demuestran que la mayoría de las personas declaraba ante la justicia tener un estado civil correspondiente a la soltería; a lo largo de las décadas estudiadas, lo fundamental era determinar la ubicación social de un individuo. Los registros disponibles muestran una relación entre la soltería y los delitos sobre la infancia perseguidos. En algunos sumarios, las explicaciones de los imputados fueron el abandono de la pareja y la consecuente precariedad económica ${ }^{13}$.

Las columnas octava a la décima de la tabla expresan que la mayoría de las sujetos formalizadas como reos, dieron cuenta que no sabían leer ni escribir, tanto al momento de presentarse al juzgado como al firmar sus declaraciones. La tabla también contribuye a demostrar que, a lo largo del siglo XIX, existieron grupos de personas que solo sabían firmar o leer. Resulta interesante conocer que solo un $22,6 \%$ de las imputadas ( 7 sumarios), manifestaron el dominio de ambas habilidades.

Las columnas once y doce de la tabla se conformaron en base a los antecedentes biográficos relevantes para la forma en que la justicia trató a los investigados. Al comienzo de los expedientes, la mayoría de los involucrados en los juicios no contaba con detenciones o participaciones previas en delitos, es decir, era la primera

${ }^{13}$ Como ha señalado Daniel Palma, en el caso de los ladrones ingresados a prisión, la ausencia de lazos sentimentales y la condición de soltería fueron parte del perfil social de quienes cometieron delitos, en este caso, contra la propiedad. Palma, Daniel, Ladrones. Historia socialy cultura del robo en Chile, 1870-1920 (Santiago, Lom Ediciones, 2011), pp. 142-154. 
vez que estaban presos. En los sumarios, los encausados que indicaron conflictos anteriores corresponden a dos hombres que habían cometido infracciones a la ley de alcoholes.

\section{EL ABANDONO DE INFANTES Y LA INVESTIGACIÓN JUDICIAL DEL DELITO}

En 1861, el diario El Ferrocarril publicaba la denuncia de un párvulo de pocos meses abandonado en una acequia, sin saber si había sido arrojado vivo o muerto a este sitio. La acusación señala que la policía realizaba indagaciones para descubrir al responsable de tal acción o el paradero de la madre ${ }^{14}$. Las notas de prensa no solo permiten apreciar la crítica moral hacia los progenitores por cometer estos actos de abandono, sino la ausencia de cualquier sentimiento de la familia por entregar una sepultura o, simplemente, perpetrar un crimen desamparando a la intemperie a un recién nacido. A partir de estos frecuentes casos, son dos las ideas necesarias de profundizar, la primera consiste en las posibilidades técnicas para encontrar a alguien contra quien formular cargos y, la segunda, asociada a la anterior, en conformar las pruebas para comprobar la participación en el delito.

Las publicaciones de los periódicos constituyeron una denuncia hacia la práctica de los abandonos que, a su vez, eran apreciados como historias llenas de incógnitas. Tras descubrir el cadáver de un párvulo, los relatos establecen interrogantes sobre "si fue arrojado allí después de muerto, o si envuelve alguno de esos crímenes misteriosos cuyos detalles quedan ignorados, pero que inspiran terror porque hacen presumir otros delitos" ${ }^{15}$. En un sentido, la prensa difundió la ocurrencia de estos crímenes, concentrándose en la ausencia de los responsables y en la brutalidad de la acción. Llamando la atención a la policía para que "desempeñase el oficio de aprehender a los que cometen el delito de arrojar a la calle a los recién nacidos" 16 . En este contexto de la persecución del infanticidio o el abandono con resultado de muerte se ha destacado que frente a la brutalidad de los hechos no aparecieron los condenados ni fue posible hallar a los autores.

La justicia solo pudo iniciar sumarios cuando existían evidencias irrefutables hacia una persona de haber arrojado un párvulo a una acequia. En efecto, se requería la confesión del involucrado. Margarita fue aprehendida y trasladada a prisión por sospechas de infanticidio; en su declaración, aseguraba que desembarazó a un niño de sexo masculino, nacido muerto y, en los días siguientes, le fue imposible dejar la cama porque se sentía enferma. A una compañera de trabajo de la casa le pidió que lo enterrase a la orilla de una acequia y después le dijo que solo lo "había arrojado a la acequia [y esto lo hizo] porque juzgué que no hacía mal en eso" ${ }^{17}$. Al realizar la autopsia médico legal, el especialista observó que “[...] está unido al cordón umbilical y la placenta [...] el estómago contiene una pequeña cantidad de agua. En síntesis, el párvulo ha nacido y ha muerto por inmersión en

${ }^{14}$ El Ferrocarril, Un párvulo, 3 de diciembre de 1861.

${ }^{15}$ El Independiente, Un párvulo, 7 de marzo de 1874.

${ }^{16}$ El Independiente, Un párvulo, 30 de enero de 1869.

${ }^{17}$ Archivo Nacional Histórico de Chile (en adelante ANHCh), Juzgado del Crimen de Santiago (en adelante JCS), caja 1.051, pieza 1, 1882, foja 2. 
el agua" ${ }^{18}$. De ese modo, según el informe médico, la criatura nació viva y falleció por inmersión en el agua, es decir, fue ahogado en la acequia.

Ante la prueba irrefutable de la autopsia, y frente a la interpelación, Margarita relató: "me quedé en la misma pieza en que desembaracé toda la noche, donde dormí sin apercibirme de que el niño viviera, pues, al contrario, lo he creído muerto porque no dio señales de vida"19. Estas circunstancias ilustran, de manera cruel, la ausencia de cuidados o preocupaciones por sepultar a un párvulo fallecido. Mercedes, indicada como la persona que dejó al recién nacido en la acequia, desapareció y fue imposible hallar su paradero o que se presentara a declarar; la situación fue corroborada por la dueña de casa, "la sirviente de la casa que desempeñaba el oficio de ama, sin que sepamos su apellido, ni tampoco su paradero. El colchón ordinario que dejó en la casa, no lo ha reclamado" ${ }^{20}$. En el transcurso de este sumario, la interrogante que emergió constantemente fue “¿quién es la autora de este delito?”21. Por un lado, la madre que estaba en cama sin moverse creyó muerto a su hijo, porque no lloró y ordenó enterrarlo; por el otro, Mercedes que lo arrojó a la acequia estando vivo, según se desprendía del certificado médico, que igualmente se defendía diciendo que había pensado que estaba fallecido. Finalmente, la sentencia recayó sobre la última, que "se fugó de la casa; que no ha sido habida i que no se ha presentado a pesar de haber sido llamada por edictos [...] se condena a ocho años de presidio mayor contados desde la captura con calidad de ser oída cuando se presente o sea habida"22.

En este período, uno de los límites de la justicia se relacionaba con la infraestructura y el funcionamiento burocrático. Esta condición se manifestó, como en el caso señalado, en el incumplimiento de penas. En las descripciones de prensa y en los expedientes judiciales se describe la ausencia de culpables en los delitos, específicamente en los abandonos de párvulos en acequias o en las iglesias. Para la justicia, las indagaciones finalizaban y, "aunque este hecho importa, a no dudarlo, un grave delito de alarmante frecuencia" 23 o se comprobaba el delito, por ejemplo, que existiendo "estrangulación, crimen sumamente grave i que tiene que quedar impune porque habiendo llegado la investigación a su término, no resulta mérito para proceder contra persona determinada" 24 . Estos fallos se explican, en gran medida, porque las pericias médico legales carecían de instrumentos técnicos y de la posibilidad de vincular un desembarazo con el abandono de un recién nacido. Estas coyunturas, salvo por la confesión de los responsables o la acusación directa de familiares o vecinos, impedían arribar a conclusiones científicamente sustentables sobre individuos particulares. Una serie de circunstancias que actuaban como atenuantes o agravantes. Podían ser ponderadas a partir del proceso de

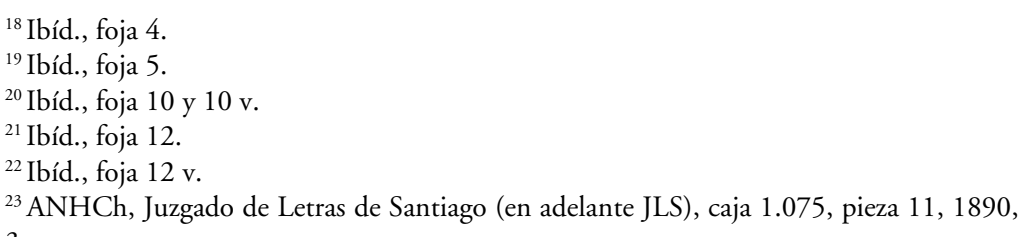
foja 3 .

${ }^{24}$ ANHCh, JLS, caja 1.114, pieza 9, 1893, foja 7 v. 
judicialización de las situaciones. En esa lógica, Margarita terminó absuelta, la justicia consideró su estado de desgaste físico y la declaración de sus patrones que la describían como una mujer intachable y haber testificado en todas las instancias requeridas. En cambio, Mercedes recibió una condena por su colaboración en el infanticidio, probablemente, por hallarse fugada y sin conformar una versión que pudiera contrastar los cargos formulados en su contra.

Interesante resulta advertir cómo fueron explicados los abandonos de los recién nacidos en las calles de la capital, y que justamente, desde la prensa liberal eran definidos bajo la dicotomía civilización y barbarie. Desconociendo la suerte que correría el párvulo, tales desamparos demostraban el carácter bárbaro de un segmento de la población. De alguna forma, las acusaciones se agravaban porque existían alternativas antes de llegar a esta determinación. Los periódicos interrogaban “¿Cuándo se convencerán las madres de familia que para ocultar su crimen tienen una Casa de Huérfanos abierta a toda hora?" ${ }^{25}$. Incluso, el Código Penal, en los artículos 347 y 348, establecía condenas para el delito de abandono, sobre todo si a consecuencia de este acto el niño sufría lesiones graves o encontraba la muerte. A pesar de las penas previstas en estos artículos "no se aplica al abandono hecho en casas de expósitos" ${ }^{26}$. De esta manera, la ley prescribió una idea, pero sus efectos dieron paso a otras situaciones.

\section{LA MUERTE DE INFANTES Y LOS DESCUIDOS EN LA CRIANZA}

El administrador del hospital del Salvador denunció que un párvulo de la sección de maternidad murió por asfixia, a causa de una estrangulación provocada por su madre. En este juicio criminal contra Melania, ella relataba que es efectiva la acusación, pues "di muerte a mi hijo a los ocho días de haber nacido en este establecimiento y me resolví a matarlo porque soi una mujer mui pobre y no tener recursos para mantenerlo; además su padre anda ausente por haberme abandonado [...] esperé que fuese la noche a fin de que nadie se impusiese" ${ }^{27}$. La autopsia ejecutada por el doctor Emilio Croizet confirmaba esta confesión, la causa precisa de muerte fue la estrangulación. A partir de estas evidencias, el juez acreditó sobre la reo el delito de parricidio e impuso la pena de muerte. El procurador apeló a este fallo y solicitó su reemplazo por la pena de presidio perpetuo. Según la defensa, la responsable tenía como atenuante la espontánea confesión y la colaboración en la investigación; su delito fue impulsado por "su estrema pobreza, que le creaba a ella i su hijo una vida de miserias i privaciones, junto con el abandono en que

${ }^{25}$ El Independiente, Párvulo, 21 de mayo de 1864. También, desde lo jurídico, revisar: Letelier, Hipólito, La protección de la infancia (Santiago, Memoria de prueba para optar al grado de licenciado en Leyes y Ciencias Políticas. Universidad de Chile, Imprenta S.B. Recoleta, 1918), p. 62.

${ }^{26}$ En línea: http://leyes-cl.com/codigo_penal/348.htm [revisado el 13 de mayo de 2018]

${ }^{27}$ ANHCh, JCS, caja 1.351, pieza 26, 1917, foja 4. Para comparar esta realidad con casos similares en Argentina, véase Ruggiero, Kristin, Maternity, and the Disciplining of Women: Infanticide in Late Nineteenth-Century Buenos Aires, en The Hispanic American Historical Review, 3 (1992), pp. 353-373. 
la dejaba el padre de la criatura"28. De algún modo, las expresiones de los reos a través de sus confesiones, peticiones de reducción de condenas o apelaciones a las sentencias, constituyen una estrategia defensiva cuyo propósito era disminuir su responsabilidad en los actos atribuidos. A ello se sumaban las redacciones de los procuradores intentando impresionar positivamente a los jueces para reducir las condenas. Por esta razón, en su relación con las autoridades penales, los inculpados, generalmente, aparecen como arrepentidos o, en su defecto, señalando que sus acciones respondieron a factores ajenos a su voluntad.

A partir de esta solicitud, el juez ordenó la realización de nuevas diligencias para llegar a un cambio en el dictamen; entre los trámites, decretó exámenes para comprobar las facultades mentales de Melania. En el desarrollo de la indagación, ella manifestó que "su padre Eulojio había muerto en un hospital y todos sabían que era malo de la cabeza; que su tío Francisco también había muerto loco; y que tanto ella como sus demás hermanos en algunas ocasiones no podían dominarse e inconscientemente ejecutaban actos censurables, de los cuales se arrepentían cuando recuperaban el discernimiento" 29 . Posteriormente, dos hermanas de la casa de corrección de mujeres encargadas de la vigilancia de la reo, aseguraron que desde su ingreso al establecimiento, Melania no había mostrado ninguna anormalidad que hiciera pensar que sus habilidades mentales estuvieran perturbadas y que tampoco había experimentado algún ataque histérico. Vistos los antecedentes hereditarios y personales de Melania, el juez concluyó que posee una debilidad mental congénita, predisposición a una locura degenerativa o epilepsia y que, durante una de esas crisis, probablemente, "cometió su crimen, en una sala común, a la vista de sus compañeros y sin la menor precaución para ocultarlo demuestran que no había conciencia del acto ni premeditación [...] el crimen ha sido cometido en un estado de inconciencia" ${ }^{30}$. Por lo tanto, quedó exenta de responsabilidad penal, fue conmutada su pena de muerte y debió ser recluida en la casa de orates, sin posibilidad de salir mientras el tribunal no lo autorizara.

María Luisa, fue denunciada por ser la madre de un feto que se encontró dentro de un excusado en un conventillo de la calle San Diego ${ }^{31}$. El desarrollo de este sumario comienza con el relato de la dueña de la propiedad, quien dio cuenta a la policía por sus sospechas, "la madre de ese feto fuera esta muchacha porque me parecía que el aumento del volumen de su vientre era un embarazo, aún cuando me habían dicho que procedía de otra enfermedad" ${ }^{2}$. Esta situación ilustra algunos significados sobre el embarazo, vinculado a un estado de enfermedad ${ }^{33}$.

${ }^{28}$ Ibíd., foja 11.

${ }^{29}$ Ibíd., foja 31.

${ }^{30}$ Ibíd., foja 59 v. y 60.

${ }^{31}$ Los conventillos eran una forma de vivienda carente de las condiciones mínimas de vida, con una infraestructura deficiente y un elevado hacinamiento, se convirtió en la representación de la cuestión social en Chile a inicios del siglo XX. Para profundizar, desde el derecho, véase: ANABAlón SANDERSon, Carlos, El problema sanitario (Santiago, Memoria de prueba para optar al grado de licenciado en la Facultad de Leyes y Ciencias Políticas de la Universidad de Chile, Encuadernación e Imprenta Colón, 1917).

${ }^{32} \mathrm{ANHCh}$, JCS, caja 1.162, pieza 2, 1896, foja 2.

${ }^{33} \mathrm{La}$ utilización del concepto enfermedad para referirse al embarazo se entendía como 
El inicio de la historia médico judicial de María Luisa tiene lugar varios meses antes, cuando entró en relaciones consideras ilícitas con Nemesio, hijo de la dueña del conventillo. Según su declaración, un día, sintiéndose con dolores al vientre, que atribuyó al consumo de sandía, se dirigió al excusado donde "me vinieron dolores que me hicieron perder los sentidos y poco después desembaracé, cayendo la criatura al depósito. Cuando pude levantarme, me fui a la cama diciéndole a mi hermana que me había dado fatiga a fin de que no se apercibiera de nada" 34 .

Para esclarecer estos hechos, la autopsia médico legal practicada por el doctor Eduardo Donoso, determinó que "el feto [...] era nacida de tiempo, ha vivido después de nacido, como lo muestra la prueba médica pulmonar. No ha sido atendida al parecer, como lo indica la ausencia de ligadura del cordón. La causa precisa i necesaria de su muerte ha sido una asfixia por sofocación" ${ }^{35}$. Con esta evidencia se pudo establecer que la niña nació viva, pero que a falta de los cuidados requeridos había muerto. Así, una de las principales interrogantes que intentaba resolver la justicia consistía en determinar si la imputada había tenido la intención de dejar perecer a la criatura. Se suponía que, "si la madre hubiera recobrado sus sentidos media hora después, ¿pudo salvarse el recién nacido? Esta es la cuestión que hai que resolver jurídicamente" ${ }^{36}$. En esa época, lo único que podía responder técnicamente la ciencia médica, era si había vivido o no, pero era imposible delimitar el período de vida de un neonato, fuesen horas o días.

El delito se encontraba en el ocultamiento de la madre tras desembarazar y recobrar el sin sentido, en ese caso, debía privilegiar al recién nacido. "Ella estaba obligada a cuidar a ese hijo; su silencio es la causa de muerte. Obra a su favor su edad i el deseo natural de ocultar su vergüenza i salvar así su honra, ya que nadie sabía que estaba embarazada" ${ }^{37}$. Legalmente, este antecedente constituía un atenuante a las penas, demostrando que la organización de las leyes estaba influenciada por el orden social en donde ocurrían los hechos, por esta razón, era importante consignar que los reos afirmaran una buena conducta en su vida. En efecto, no se logró acreditar que María Luisa diera muerte de manera voluntaria a su hijo y, por la ausencia de pruebas no era culpable del delito de infanticidio. No obstante, el promotor fiscal verificó que el parto se llevó a cabo en las condiciones que la reo señalaba en su declaración y que "dejó abandonada la criatura sin procurar recojerla ni dar aviso para que la recojiesen, omisión que la hace responsable del delito previsto en el art. 346 del Código Penal”38. De acuerdo

un período inhabilitante de las actividades laborales. Por ejemplo, "Ramón se presentó a la Comisaría, denunciando que su sirviente María había desembarazado y dado muerte a su hijo. Como ella había negado hasta última hora embrazada, trataba de ocultar su crimen fingiendo otra enfermedad". ANHCh, JLS, caja 1.114, pieza 61, 1893, foja 1.

${ }^{34}$ ANHCh, JCS, caja 1.162, pieza 2, 1896, foja $2 \mathrm{v}$.

${ }^{35}$ Ibíd., foja 4.

${ }^{36}$ Ibíd., foja 8.

${ }^{37}$ Ibíd., foja $9 \mathrm{v}$.

${ }^{38}$ Ibíd., foja 22 v. El Código Penal establece en el artículo 346: "el que abandonare en un lugar no solitario a un niño menor de siete años, será castigado con presidio menor en su grado mínimo". En línea: http://leyes-cl.com/codigo_penal/346.htm [revisado el 3 de mayo de 2018] Para profundizar, véase: AréVAlo, Francisco, El abandono en la infancia (Santiago, Memoria 
con la comprobación entregada por los informes médicos, la muerte del neonato sobrevino a consecuencia del abandono y por eso la mujer fue condenada a trescientos setenta días de presidio.

En esta época, la honra en tanto buena mujer u hombre y la conformación de su reputación se sustentaban en las costumbres manifestadas por el inculpado o por los relatos de los testigos. En los procesos de infanticidio, generalmente, se indicaba la inocencia de las agresoras, dado que se habían visto obligadas a estos actos por la vergüenza, por miedo o por algún estado nervioso. Con ese propósito, los cercanos o los testigos favorables a las victimarias, se preocupaban de insistir que ellas tenían un modo de vida apegado a las costumbres ejemplares. En esa línea, la ratificación judicial de una convivencia obediente hacia los patrones, manifestaciones de buena conducta y demostrar ser persona trabajadora, podía otorgar validez al testimonio y ser percibido, por los encargados de impartir justicia, como una prueba fiable de los hechos.

El caso de Ema fue uno de los registros que muestra la distancia entre la madre y el recién nacido durante el embarazo. Ella señalaba que: "por vergüenza, oculté siempre mi estado y usaba delantales amplios en forma de batas, comprimiéndolo así, nunca notando nada en dicha casa" ${ }^{39}$. En realidad, quería mantener en secreto esta situación y no ser obligada a delatar su condición. Cuando relata el momento del parto, destacaba que lo llevó a cabo sin la asistencia de ninguna persona y que observó que la criatura nació con vida, pero no lloraba. Además, sostuvo que: "hice mis quehaceres como de costumbre i dejé allí al (feto) párvulo, no atreviéndome a botarlo o mandarlo a enterrar por temor a ser descubierta" ${ }^{40}$. A continuación, lo depositó en una caja con ropa, hasta ser encontrado por sus empleadores, quienes dieron cuenta a la policía. Este caso refleja los rasgos de desapego y abandono manifestados por la madre. Pese a experimentar la presión social y los riesgos del parto en la época, una vez producido el nacimiento, se desprende de sus palabras que no se preocupó, mayormente, por la suerte del recién nacido. Sus acciones dan cuenta de una internalización de la cultura del período, que incluía como alternativas la posibilidad de botarlo o enviarlo a enterrar, aun consciente de la penalidad de estos hechos. La judicialización respalda este relato, ya que el sobreseimiento temporal del sumario para aclarar las causas de muerte de éste recién nacido, argumentó "no aparece comprobado que hubiera habido delito en el hecho investigado" 41 . De esa manera, cuando la justicia dispuso de las confesiones y la identificación de una persona responsable, tampoco logró condenas efectivas por infanticidio, principalmente por las escasas herramientas técnicas y las desprolijidades para llevar a cabo las pesquisas.

Durante la segunda mitad del siglo XIX, era frecuente que los padres de buena situación económica entregaran sus hijos a nodrizas para la crianza o para que se hicieran cargo de la alimentación; en estas situaciones, la familia acordaba un

de prueba para optar el grado de licenciado en la Facultad de Leyes y Ciencias Políticas de la Universidad de Chile, 1918).

${ }^{39}$ ANHCh, JCS, caja 1.355 , pieza 21,1917 , foja $1 \mathrm{v}$.

${ }^{40}$ Ibíd., foja 2.

${ }^{41}$ Ibíd., foja 6. 
salario mensual por estos servicios. El mismo sistema ocupaba la casa de huérfanos conviniendo un pago cada mes por los cuidados sobre cada infante. Los problemas se originaban cuando las mujeres que llevaban a cabo tal labor sufrían la muerte del párvulo a su cargo, transformándose en sospechosas de infanticidio. Tales fueron las circunstancias de una nodriza que criaba a una niña y que acudió a la casa de su padre con el cadáver de la infante, "como presentaba algunas contusiones y pequeñas heridas en el cuello y al lado del pecho, la cuidadora fue aprehendida y conducida en seguida al cuartel de San Pablo, en donde ha sido puesta a disposición del juez del crimen, mientras se esclarecen los pormenores del suceso y la culpabilidad que pueda recaer en ella por la muerte"42.

En 1895, Elena se presentó en la comisaría exponiendo que Vitalicia, ama de leche que contrató, le dio de golpes al niño de tres meses de edad que cuidaba, infiriéndole contusiones graves que le provocaron la muerte. Llamada a testificar, la madre del párvulo dijo que "tenía fuertes presunciones que la nodriza era la causante de aquellas contusiones que ella había visto que la misma nodriza apretaba fuertemente al niño y que una noche, después de regresar de una visita, encontré al niño en estado de aturdimiento y teniendo un quejido constante" ${ }^{\text {"3 }}$. Reiteró el mal trato que la acusada daba a la criatura, ya que en más de una ocasión fue sorprendida golpeando al niño. A ello se sumó la declaración del doctor Emilio Rodríguez Cerda, citado para atender profesionalmente a un enfermo. Sin embargo, se halló con el párvulo fallecido y pudo reconocer contusiones de carácter serio en toda la región de la espalda, en el dorso y en dos o tres en las regiones occipitales y parietales.

Por su parte, el doctor Moisés Salas también fue llamado para examinar al mismo niño, diagnosticando "una afección cerebral [...] noté una fiebre de cerca de cuarenta grados, pulso irregular, respiración irregular, falta de reacción pupilar, movimiento oscilatorio de la cabeza, síntomas todos consecutivos de la afección" ${ }^{4}$. No obstante, llama la atención los métodos empleados por el especialista en su análisis, "no desnudamos al niño y por este motivo no vimos si tenía contusiones en su cuerpo [...] En presencia de los síntomas que observamos y dado los antecedentes hereditarios tuberculosos (una tía murió de tuberculosis pulmonar) creímos se trataría de una meningitis tuberculosa” ${ }^{45}$. Esta fue la única vez que revisó al niño y no lo volvió a ver después. A continuación, trató al infante el doctor Justo Merino, quien confirmó los indicios señalados y concluyó que padecía una meningitis tuberculosa, formulando un pronóstico fatal.

Este caso revela los vínculos entre los médicos y la población, apreciados a través del lente de la justicia. La asistencia entregada a las madres durante las enfermedades de la niñez permite verificar las características del ejercicio de la medicina en la infancia a fines del siglo XIX. Las descripciones del doctor Justo Merino demuestran el contacto entre ambas tradiciones y destaca la forma de suministrar los medicamentos: "dejé de ver al enfermo dos o tres días, transcurridos los cua-

\footnotetext{
${ }^{42}$ El Ferrocarril, Cadáver de un párvulo, 25 de octubre de 1885.

${ }^{43} \mathrm{ANHCh}$, JCS, caja 1.148, pieza 51, 1895, foja 2.

${ }^{44}$ Ibíd., foja 4.

${ }^{45}$ Ibíd., foja $4 \mathrm{v}$.
} 
les fui llamado nuevamente, pudiendo en esta ocasión ratificar nuestro anterior diagnóstico, llamándome la atención la incuria o torpeza en la aplicación de los medicamentos prescriptos en la visita anterior. En efecto, un papelillo de carbón en el ano, que en la anterior visita le fue prescripto para dárselo por la boca, como claramente a la madre le fue indicado [...] purgantes con aceite i lavados intestinales que también fueron prescriptos no se le administró" ${ }^{46}$. Como consecuencia, los médicos advirtieron la pérdida de efectividad de los tratamientos por su mal empleo, incumplimiento de los tiempos entre las dosis, mal fraccionamiento de las cantidades o, simplemente, la omisión de los remedios.

Finalmente, tras las declaraciones de ambos médicos y sin una autopsia médico legal, afirmaron que el infante falleció por una afección cerebral y en el cadáver no se observaron lesiones originadas por golpes o presiones. Siguiendo la evolución de este expediente, entre los médicos, los juristas y los encargados de transcribir las declaraciones se produjeron intercambios de conceptos, por ejemplo, en algunas fojas aparece como causa de muerte una afección cerebral y en otras se detalla que el deceso se produjo por tuberculosis pulmonar. En síntesis, no se conformaron los antecedentes para proceder criminalmente contra Vitalicia, como responsable de la muerte del niño Florencio, porque dejó de existir a consecuencia de enfermedad natural.

\section{EL INFANTICIDIO BAJO EL LENTE DE LA MEDICINA LEGAL}

Las relaciones entre la justicia y la medicina se han considerado fundamentales a la hora de analizar los juicios por infanticidio durante el siglo XIX y comienzos del XX. Al respecto, los jueces desarrollaron conjeturas cuya solución requería conocimientos específicos, ajenos a la preparación jurídica. De ahí que solicitaron informes a los médicos para confirmar las características de las lesiones que abrían el sumario ${ }^{47}$. El resultado se daba a partir del informe médico legal que contenía las evaluaciones y exámenes respaldados en la experticia ${ }^{48}$. La producción de evidencias, su contrastación y la exhibición de hallazgos para sostener determinados puntos de vista podrían ser modificadas ante la aparición de nuevas pruebas $\mathrm{u}$ omisiones de algunos trámites ${ }^{49}$. En los sumarios, esta trayectoria llevaría a cambios en los criterios o en la forma de ponderar ciertos eventos.

${ }^{46}$ Ibíd., foja 5 v.

${ }^{47}$ Según el Código de Procedimiento Civil (28 de agosto de 1902), artículo 411: "Se oirá el informe de peritos en todos aquellos casos en que la ley asi lo disponga, ya sea que se valga de estas expresiones o de otras que indiquen la necesidad de consultar opiniones periciales". [Sin autor identificado], Lejislación chilena sobre medicina legal (Santiago, Imprenta Cervantes, 1907), p. 8.

${ }^{48}$ Según el artículo 147 del Código de Procedimiento Penal, "los médicos deben expresar en su informe las causas inmediatas que hubieren producido la muerte y las que hubieran dado origen a ésta. Si existen lesiones, deben manifestar su número, longitud y profundidad, la región en que se encuentran y los órganos afectados". También explicitaba que los informes debían estar redactados, en cuanto fuera posible, en lenguaje vulgar. [Sin autor identificado], Lejislación, cit. (n. 47), p. 63.

${ }^{49}$ En esta época, la falta coordinaciones entre la esfera legal y médica generó desprolijidad en las investigaciones. En esa línea, el doctor Juan del Carmen Sierra señaló que fue "llamado por el juez de primera instancia, para que removiera un feto de todo tiempo que se encontraba 
A nivel jurídico, las disputas tuvieron como punto de partida el momento en que los tribunales de justicia otorgaron al informe médico una valoración equivalente a un testigo y ambos eran considerados como medios de prueba con igual ponderación durante un juicio ${ }^{50}$. Para los abogados, a pesar que los dos eran considerados por el tribunal, esta situación era errónea ya que "a fin de que se forme un juicio cabal del asunto en debate, la índole de ambas informaciones es opuesta, ya que se diferencian por el carácter técnico de las emitidas por los peritos" ${ }^{51}$. El Código de Procedimiento Civil y el Penal prescribieron la obligación que tenía el juez de escuchar el dictamen de expertos, generalmente médicos, en todas aquellas materias enumeradas por las leyes.

La necropsia médico legal se desarrolló por disposición judicial para esclarecer la ocurrencia de un crimen, determinar su producción por vía natural, accidente o por una acción delictual. Así, estos informes eran fundamentales para las sentencias de los hechos criminales. Dada la orden de los juzgados, los médicos eran los encargados de ejecutar las autopsias y exponer el resultado de sus peritajes, a partir de los cuales se establecía, científicamente, las razones precisas del deceso. Para los médicos de ciudad el trabajo práctico en el cadáver fue un elemento decisivo en las trayectorias de las investigaciones; el especialista debía explicar las contusiones patológicas o las de categoría criminal, para lo cual requería dominar conocimientos y contar con un instrumental apropiado. Según el doctor Francisco Landa, "las autopsias se hacen con la mayor corrección posible, descubriendo e interpretando las lesiones una a una hasta llegar a la causa precisa y necesaria de la muerte" 52 .

Para emitir un informe, el médico de ciudad debía observar y reconocer indicios en el cadáver con la finalidad de reconstruir los hechos que generaban la judicialización. Desde el examen a simple vista hasta el análisis detenido de los órganos, no omitiría datos que podrían significar componentes relevantes en una investigación judicial. No obstante, los trámites estuvieron expuestos al deterioro de las evidencias, por ejemplo, cuando la autopsia no se realizaba en el momento del crimen y/o por las falencias técnicas que impedían la identificación plena de

en la cárcel, cuya autopsia no hizo, pues el mismo juez le dijo que no era necesario". ANHCh, JCS, caja 1.148, pieza 51, 1895, foja 20.

${ }^{50}$ Código de Procedimiento Penal, artículo 245 "El juez pedirá informes de peritos en los casos determinados por la Ley, y siempre que, para apreciar algún hecho o circunstancia importante, fueren necesarios o convenientes conocimientos especiales de alguna ciencia, arte u oficio". En nuestra legislación penal, el mérito probatorio quedaba entregado al criterio del juez. Sin embargo, para que pueda dar valor al informe deberá ponderarlo a fin de cerciorarse si concurren o no los requisitos que exige el artículo 472 del Código de Procedimiento Penal, los cuales eran: existencia de dos informes acordes, que afirmen con seguridad la existencia del hecho, que este hecho lo hayan observado o deducido con arreglo a los principios de la ciencia, arte u oficio que profesen y que estos informes no estén contradichos por otros. [Sin autor identificado], Lejislación, cit. (n. 47), p. 11.

${ }^{51}$ Cuevas, Luis, La pericia médico-legal. Sus imperfecciones en la práctica (Santiago, Imprenta i Encuadernación La Economía, 1921), p. 16.

${ }^{52}$ Las Últimas Noticias, La morgue y el Instituto de medicina legal. La opinión del doctor Landa, 26 de mayo de 1913. 
algunas huellas o la distinción entre la sangre humana y la animal. A consecuencia de esto, la calidad de los registros era discutible y, con ello, modificaba las interpretaciones en el ámbito judicial.

Desde el punto de vista médico legal, los peritajes científicos a los pulmones eran fundamentales para la constitución de evidencias jurídicas. Mediante una prueba dosimétrica se confirmaba el ingreso de aire o su ausencia en el cuerpo de la víctima. Para lograr la aplicación efectiva de este proceso, el facultativo introducía los pulmones en un recipiente con agua, si flotaban significaba la presencia de aire en este órgano, en caso contrario, el hundimiento representaba la nula respiración. A nivel médico, esta parte del análisis, permitía delimitar físicamente entre la vida o la muerte de la persona. Con esta comprobación certificaban, de manera irrefutable, las causas precisas de una muerte. Estos exámenes podían arrojar una "conjestión de sangre de los pulmones" 53 o "muerte por asfixia durante el parto, pues solo hai signos de una respiración incompleta" 54 , en estos casos las evidencias llevaban al sobreseimiento.

Los especialistas médicos determinaron, en el caso de las agresiones que ocasionaron la muerte del infante, establecer el momento en fueron provocadas, las armas o instrumentos utilizados y otros factores relevantes en la investigación. Para la administración de justicia penal, se creaba el problema respecto a la constatación del acto delictuoso y sus circunstancias, permitiendo al magistrado tomar conciencia cabal sobre la magnitud del crimen, el simple delito y las condiciones que agravaron o atenuaron el suceso ${ }^{55}$. Efectivamente, este trabajo hacía posible distinguir entre las heridas que fueron mortales per ser y las que ocurrieron por accidente, es decir, las que podrían ser tratadas y mejoradas, pero que llegaron a producir la muerte por la prescripción incorrecta de un medicamento o el resultado de una operación quirúrgica efectuada de manera negligente.

Los jueces gozaron de amplias facultades para realizar averiguaciones, citar testigos, solicitar diligencias y obtener declaraciones para arribar a la verdad jurídica. En estos litigios, se presentaron dos situaciones que dificultaron la aplicación de condenas a los imputados: las normas inflexibles que se impusieron en la evaluación de la calidad de las pruebas y la precariedad de estas evidencias que impedían vincular directamente a una persona con la ocurrencia de un delito. Así, la tramitación judicial por infanticidio sugiere que, en la mayoría de los casos, una de las primeras diligencias fuera la prisión preventiva a consecuencia de múltiples indicios que generaban las sospechas de que el imputado tenía responsabilidad en los hechos indagados. Sin embargo, la complejidad que enfrentaron los jueces para comprobar las interrogantes y la potencial culpabilidad, surgidas en la apertura de los expedientes se iban desarticulando a medida que las investigaciones progresaban, ya que no se cumplían los niveles de certidumbre exigidos como criterios para formar una verdad jurídica, lo que consecuentemente determinaba el sobreseimiento en la mayoría de los sumarios.

\footnotetext{
${ }^{53}$ ANHCh, JCS, caja 1.009, pieza 38, 1874, foja 2.

${ }^{54}$ ANHCh, JCS, caja 1.047, pieza 29, 1886, foja 2.

${ }^{55} \mathrm{El}$ Mercurio, Informes médicos en los procesos criminales, 3 de junio de 1908.
} 


\section{CONCLUSIONes}

Para abordar el problema de la mortalidad infantil a través de la justicia, en este artículo se han analizado y descrito cuatro grandes temáticas desarrolladas desde las experiencias. En primer lugar, los abandonos de párvulos, vivos o muertos, en diversos espacios de la ciudad, los que generaron investigaciones a las que concurrieron múltiples testigos y se respaldaron en la realización de las autopsias. En general, se trató de procesos técnicamente precarios, donde las pruebas legales se caracterizaron por la baja calidad o su ausencia. Este factor impidió que los sumarios, a pesar de individualizar un responsable, llegaran a formar la convicción en los jueces al momento de condenar, y, por lo tanto, concluyeron en sobreseimientos. Muy cercano a ello, en segundo lugar, estuvieron los modos de crianza enmarcados en grupos familiares que tomaron la decisión de entregar un niño a una de las nodrizas quien, a cambio de sus cuidados, encontraba un medio de subsistencia. Algunas de estas relaciones terminaron dramáticamente, cuando se produjo una muerte por maltratos o accidentes. En tercer lugar, y en relación a la crianza por encargo, la falta de vigilancia materna como causal de las muertes en los párvulos representó, en parte, los descuidos maternos hacia la infancia y los partos sin asistencia médica. Tanto los enredos como la falta de probidad de empleados públicos, especialmente desde la jefatura, como igualmente la falta de incentivos y de presupuestos para modernizar los equipos de la medicina legal, fueron factores que se unieron a causales sociales y/o culturales en la indefensión de los niños por nacer o de los nacidos.

La colaboración de los testigos se efectuaba solo cuando existían indicios de participación en los delitos o se trataba de personas cercanas a los potenciales responsables. En la configuración del sistema judicial, los jueces entendían que su desempeño se encontraba frente a múltiples limitaciones técnicas para abordar las investigaciones. La mayor parte de las pericias ponían énfasis en las palabras de los involucrados y la autopsia médico legal; por lo tanto, no había otra clase de prueba que permitiera definir la intervención en los hechos. A pesar del esfuerzo de la policía para realizar las indagatorias, esta institución ejerció su labor en un entorno burocrático con procedimientos poco claros y sin roles delimitados para cada funcionario. Por esta razón, los sumarios a menudo llegaban al sobreseimiento a pesar de tener presunciones fundadas sobre un culpable. Las clausuras de los expedientes reforzaban las condenas morales y los significados bárbaros de los actos, pero raramente llegaron a castigar a un individuo y tampoco incidieron en la ocurrencia de estas prácticas hasta las primeras décadas del siglo XX.

La violencia hacia la infancia, a través de la judicialización por infanticidio, constituye un escenario que permite entender la experiencia de los niños que lo sufrieron y origina el contexto en que se produjo una elevadísima mortalidad infantil. Culturalmente podía implicar malos los tratos de las madres o los encargados del cuidado en los recién nacidos, el desapego o el abandono sobre los párvulos. Cadáveres dejados en iglesias, golpes, inanición, errores en los medicamentos, fueron parte de las atrocidades infringidas a los niños durante la segunda mitad del siglo XIX. Los sumarios no alcanzan a mostrar la totalidad de los hechos, 
aunque contienen informes de los que llegaron a la justicia y entregan relatos que intentaban guiar el camino hacia la verdad jurídica.

A partir de los registros que entregan los expedientes judiciales, los cambios producidos en los tratos hacia la infancia se encuentran respaldados, a nivel de prácticas y representaciones culturales, en el proceso de medicación y en la instalación de las lógicas para prodigar cuidados a los párvulos. Modificaciones que tardaron varias décadas, entre fines del siglo XIX e inicios del XX y se tradujeron en la fundación de hospitales, mejoras en las construcciones habitacionales y en las formas de alimentar a los niños, entre otros factores, que contribuyeron a disminuir las elevadísimas tasas de mortalidad infantil, consolidando a la pediatría como un campo médico especializado en el tratamiento de las enfermedades infantiles.

\section{BiBLIOGRAFÍA}

Albornoz, María Eugenia, Experiencias de conflicto: subjetividades, cuerpos y sentimientos en Chile, siglos XVIII y XIX (Santiago, Acto Editores, 2015).

Anabalón Sanderson, Carlos, El problema sanitario (Santiago, Memoria de prueba para optar al grado de licenciado en la Facultad de Leyes y Ciencias Políticas de la Universidad de Chile, Encuadernación e Imprenta Colón, 1917).

Arévalo, Francisco, El abandono en la infancia (Santiago, Memoria de prueba para optar el grado de licenciado en la Facultad de Leyes y Ciencias Políticas de la Universidad de Chile, 1918).

Avilés Mejías, Víctor, Obstetricia forense (Santiago, Ediciones de Derecho Moderno, 1968).

CASARInI, María Pía, Maternità e infanticidio a Bologna: fonti e linee di ricerca, en Quaderni Storici, 49 (1982), pp. 275-284.

Cuevas, Luis, La pericia médico-legal. Sus imperfecciones en la práctica (Santiago, Imprenta i Encuadernación La Economía, 1921).

Di BLASIO, María Pina, L' infanticidio nella legislazione penale: uno sguardo al passato per capire il presente, en Giurisprudenza Penale (2016). En línea: http://www.giurisprudenzapenale.com/2016/03/23/linfanticidio-nella-legislazione-penale-uno-sguardo-alpassato-capire-presente/ [revisado el 23 de junio de 2018].

DiDIER, Alejandra, Dreckmann, Alejandra y García, Jackeline, No olvidar el montón de pequeños cuerpos enterrados sin nombre: muerte de niños a través de protocolos de autopsia de la morgue de Santiago (1910-1912), en Investigación forense (Servicio Médico Legal), 2 (2011), pp. 43-60.

Domínguez Larraín, Manuel, El infanticidio desde el punto de vista penal y médico legal (Santiago, Memoria de prueba para optar al grado de licenciado en la Facultad de Leyes y Ciencias Políticas, Universidad de Chile, Sociedad Imprenta y Litografía Universo, 1922).

Gajardo, Samuel, Definiciones y sintesis de medicina legal (Santiago, Editorial Universo, 1946).

- Medicina legal y psiquiatría forense (Santiago, Editorial Nacimento, 1931).

Ginzburg, Carlo, Tentativas (Rosario, Prohistoria Ediciones, 2004).

Higginbotham, Ann, Sin of the age: infanticide and illegitimacy in Victorian London, en Victorian Studies, 3 (1989), pp. 319-337. 
HUNECKE, Volker, Intensità e fluttuazioni deglil abbandoni dal XV al XIX secolo". Enfance abandonée et société en Europe (Rome, École Française en Rome, 1991).

IPINZA Besoaín, Arnaldo, De la natalidad ilegitima. Sus causas y modo de remediarlas (Santiago, Memoria de prueba para optar al grado de licenciado en la Facultad de Leyes y Ciencias Políticas de la Universidad de Chile, Imprenta San José, 1920). Lejislación chilena sobre medicina legal [Sin autor identificado], (Santiago, Imprenta Cervantes, 1907).

Letelier, Hipólito, La protección de la infancia (Santiago, Memoria de prueba para optar al grado de licenciado en Leyes y Ciencias Políticas. Universidad de Chile, Imprenta S.B. Recoleta, 1918).

Milanich, Nara, Entrañas mil veces despreciables e indignas. El infanticidio en el Chile tradicional, en Dimensión histórica de Chile, 13-14 (1997-1998), pp. 63-82.

-Children of fate. Childhood, class, and the State in Chile, 1850-1930 (Durham, Duke University Press, 2009).

OlIVIERI, Ilaria, L'infanticidio tra percezione popolare e trattamento giuridico: Prignano 1889, en Storicamente, 6 (2010). En línea: http://dx.doi.org/10.1473/stor71 [revisado el 12 de junio de 2017].

Palma, Daniel, Ladrones. Historia social y cultura del robo en Chile, 1870-1920 (Santiago, LOM Ediciones, 2011).

Puga Borne, Federico, Compendio de medicina legal adaptado a la lejislación chilena (Santiago, Imprenta Cervantes, 1896).

Revuelta, Bárbara, Abandoned and illegitimate, a double mortality penalty? Mortality of illegitimate infants in the foundling hospital of Madrid, La Inclusa (1890-1935), en Journal The History of the Family, 18 (2013), 44-67.

Ruggiero, Kristin, Maternity, and the Disciplining of Women: Infanticide in Late Nineteenth-Century Buenos Aires, en The Hispanic American Historical Review, 3 (1992), pp. 353-373.

Salinas, René y Delgado, Manuel, Los hijos del vicio y del pecado: la mortalidad de los niños abandonados (1750-1930), en Proposiciones, 19 (1990), pp. 44-54.

Sargas Guerra, Eduardo, La ilejitimidad en Chile i sus consecuencias (Santiago, Memoria de prueba para optar al grado de licenciado en la Facultad de Leyes i Ciencias Políticas de la Universidad de Chile, Imprenta Camilo Henríquez, 1917).

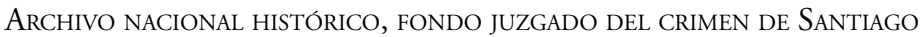

Sobre la muerte de un párvulo, caja 1.009, pieza 38, 1874.

Indagatorio sobre la muerte del párvulo n.n., caja 1.047, pieza 29, 1886.

Contra Margarita Rojas por parricidio, caja 1.051, pieza 1, 1882.

Muerte del niño Florencio Vásquez, caja 1.148, pieza 51, 1895.

Lesiones a la niñita Sara Ramírez, caja 1.162, pieza 2, 1896.

Infanticidio, caja 1.351, pieza 26, 1917.

Contra Ema Pérez por infanticidio, caja 1.355, pieza 21, 1917.

Archivo nacional histórico, fondo JUZGado de letras de Santiago

Muerte del párvulo n.n. encontrado en la calle de Morandé, caja 1.075, pieza 10, 1890. Muerte del párvulo n.n. del sexo femenino encontrado en la calle de la Compañía, caja 1.075 , pieza $11,1890$.

Muerte de un párvulo encontrado en la avenida Latorre, caja 1.114, pieza 9, 1893. Infanticidio, caja 1.114, pieza 61, 1893. 